\title{
Splenectomy in patients with undiagnosed splenomegaly
}

\author{
C.C. Cronin, M.P. Brady', C. Murphy, E. Kenny, M.J. Whelton and \\ C. Hardiman
} Departments of Medicine and Haematology, and ${ }^{1}$ Department of Surgery, Regional Hospital, Cork,
Ireland

\begin{abstract}
Summary: Of splenectomies performed in the Cork Regional Hospital over an 11 year period, ten were undertaken primarily for diagnostic purposes. A definitive histological diagnosis was established in nine patients, seven of whom had lymphoma, two with Hodgkin's disease and five with non-Hodgkin's lymphoma. The weight of the excised spleen in all patients with lymphoma exceeded $1 \mathrm{~kg}$; in all those with a diagnosis other than lymphoma, the spleen weighed less than $1 \mathrm{~kg}$. A majority of patients also had symptomatic improvement from reversal of hypersplenism and from relief of the mechanical pressure effects of an enlarged spleen. Operative mortality was zero.
\end{abstract}

Diagnostic splenectomy is a worthwhile procedure. Most patients will have lymphoma.

\section{Introduction}

Appropriate investigation in most patients with undiagnosed splenomegaly will yield a diagnosis. When conventional investigative techniques fail, resort to surgical removal of the enlarged spleen may be required. We have reviewed the patients who underwent diagnostic splenectomy in the Cork Regional Hospital during the years 1981-1991 inclusive.

\section{Patients and methods}

The charts of patients who underwent splenectomy in the Cork Regional Hospital during the years 1981 to 1991 , inclusive, were reviewed. The list of patients was compiled from perusal of theatre lists, of pathology reports and of the diagnostic index of the medical records department. The patients' hospital notes were reviewed and those whose operation was primarily for diagnostic purposes were isolated.

The total number of splenectomies was 136 . The hospital records of eight patients who had died before 1985 had been incinerated; the records of an additional five patients could not be located. A total of 123 charts were, therefore, reviewed. The indications for splenectomy were traumatic injury (50 patients, $41 \%$ of total), haematological conditions (38 patients, $31 \%$ ) and unplanned splenec-

Correspondence: C. Cronin, M.B., M.R.C.P.I., Department of Medicine, Cork Regional Hospital, Wilton, Cork, Ireland.

Accepted: 27 September 1993 tomy during abdominal surgery (intra-operative trauma and surgery for abdominal neoplasia) (25 patients, $20 \%)$. Ten patients $(8.1 \%)$ underwent splenectomy primarily for diagnostic purposes and are presented here.

\section{Results}

The majority of the patients who had a diagnostic indication for splenectomy had lymphoma (Table I), five with non-Hodgkin's lymphoma and two with Hodgkin's disease. Preoperative investigations in the patient with hairy cell leukaemia did not indicate this diagnosis. The patient with congestive splenomegaly was suspected preoperatively to have a connective tissue disease or an infiltrative splenomegaly. One spleen showed no abnormal histological features.

The average age of the patients who had splenectomy for diagnostic purposes was 52 years (range 21-68 years). Six were male and four female. The mean known duration of splenomegaly before surgery was 9.4 months (range 1-36 months). All 10 patients had had a marrow aspirate and biopsy performed before surgery. Seven patients had had a percutaneous liver biopsy and one a scalene node biopsy. Eight patients had undergone abdominal computed tomography (CT) scanning and two abdominal ultrasonography. In no case had these or other investigations provided a definitive diagnosis.

The mean weight of the excised spleens was $1.7 \mathrm{~kg}$ (range $0.3-3.5 \mathrm{~kg}$ ). Three spleens weighed less than $1 \mathrm{~kg}$, each from a patient with a diagnosis 
Table I Gender, age, final diagnosis and spleen weight in patients who had splenectomy

\begin{tabular}{llclr}
\hline Patient & Gender & $\begin{array}{c}\text { Age } \\
\text { (years) }\end{array}$ & \multicolumn{1}{c}{ Diagnosis } & $\begin{array}{c}\text { Weight } \\
(\mathrm{g})\end{array}$ \\
\hline 1 & Female & 59 & Hodgkin's disease & 2,500 \\
2 & Male & 51 & Non-Hodgkin's lymphoma & 1,700 \\
3 & Female & 66 & Hodgkin's disease & 2,000 \\
4 & Male & 49 & Hairy cell leukaemia & 520 \\
5 & Male & 38 & Non-Hodgkin's lymphoma & 3,120 \\
6 & Male & 61 & Non-Hodgkin's lymphoma & 1,220 \\
7 & Female & 67 & Non-Hodgkin's lymphoma & 1,575 \\
8 & Female & 56 & Splenic congestion & 308 \\
9 & Male & 52 & Normal histology & 675 \\
10 & Male & 21 & Non-Hodgkin's lymphoma & 3,500 \\
\hline
\end{tabular}

other than lymphoma; the weight of the spleen of every patient with lymphoma exceeded $1 \mathrm{~kg}$ (see Table I).

Postoperative complications included a septicaemic illness and bilateral calf deep venous thromboses. One patient required revision of the surgical scar for entrapment neuropathy. Operative mortality was zero.

Eight patients were transfusion-dependent or had a haemoglobin of less than $12 \mathrm{~g} / 100 \mathrm{ml}$ before surgery. Five patients had pancytopenia. Because of the influence of perioperative blood transfusion and, in most patients, postoperative chemotherapy, it is not possible to determine the effects of splenectomy on the formed elements of the peripheral blood accurately; the trend in most patients, however, was one of improvement.

Postoperatively, eight patients received chemotherapy. Two patients have died, one from non-Hodgkin's lymphoma and one from hairy cell leukaemia. The other eight patients remain well (mean of 4.2 years postsplenectomy). The patient whose spleen showed normal histology is now 10 years postoperative and in normal health.

\section{Discussion}

In any hospital, the proportion of splenectomies performed for diagnostic or for any other indication will vary with referral patterns. The indications for splenectomy have changed over recent years, in particular for haematological conditions. ${ }^{1}$ Splenectomy for the staging of Hodgkin's disease, for example, is now rarely performed. Improved diagnostic facilities, particularly better imaging techniques and greater use of percutaneous tissue aspiration and biopsy, have reduced the necessity for diagnostic splenectomy. Many conditions mentioned in previous series of diagnostic splenectomy, such as splenic cysts and abscesses, sarcoidosis and
Gaucher's disease $\mathrm{e}^{2-4}$ would now in many instances be diagnosed without recourse to surgery. Despite these factors, the figure of $8.1 \%$ of all splenectomies for diagnostic purposes is similar to previous reports, extending over the past two decades. $^{2-4}$

Although the primary purpose of splenectomy in these patients was diagnostic, a therapeutic element was often present. Many of the patients gained relief from hypersplenism and from the mechanical effects of an enlarged spleen (abdominal discomfort and early satiety). A rapidly enlarging spleen is also at risk from rupture and from recurrent splenic infarction. In many haematological conditions, in addition, as in lymphoma confined to the spleen, splenectomy may be therapeutically beneficial. ${ }^{5}$

The primary objective of splenectomy in this type of patient is positive histopathological diagnosis, which was achieved in nine of our patients and a definitive clinical diagnosis was obtained in all ten patients. Improved general diagnostic techniques, allowing diagnosis of many other conditions without recourse to surgery, probably account for the higher incidence of lymphoma in our series in comparison to previous reports. ${ }^{2,3,6}$ Dacie et al. have emphasized the high incidence of lymphoma in patients with 'non-tropical idiopathic splenomegaly', which in many instances may not become apparent until years after surgery. ${ }^{6.7}$

Splenomegaly without peripheral lymphadenopathy is the presenting feature in less than $1 \%$ of cases of lymphoma. ${ }^{8}$ Such patients with normal blood counts postsplenectomy may have a particularly good prognosis ${ }^{9}$ and surgery alone may be curative. ${ }^{5}$ Conversely, most cases of lymphoma confined to the spleen are diagnosed only at the time of splenectomy, whether suspected or not preoperatively. In the series of Kehoe and Straus, of 21 patients with primary lymphoma of the spleen, the diagnosis was confirmed only after 
surgical excision, although unsuspected in 13 patients. ${ }^{10}$

In recent years, developments in cellular and molecular biology have provided several tools that allow more sensitive and specific examination of neoplastic lymphoid tissue, providing diagnostic and prognostic information. ${ }^{11,12}$ The application of these techniques may allow a diagnosis of lymphoma to be made in patients who would previously have been classified as 'non-tropical idiopathic splenomegaly'.

A greater understanding of the complications of splenectomy and better management of the asplenic patient have made splenectomy a less daunting procedure. The fear of overwhelming postsplenectomy sepsis may have been overemphasized, particularly in adults. ${ }^{13,14}$ In this series no patient has (as yet) suffered from the longer term consequences of the asplenic state. It is our practice routinely to administer pneumococcal vaccine preoperatively and to continue penicillin prophylaxis for at least 2 years postoperatively. In the future, $H$. influenzae type $b$ vaccine and meningococcal vaccine against the $a$ and $\mathrm{c}$ strains may be considered appropriate. ${ }^{15}$

In addition to the risk of postsplenectomy sepsis, patients who have had diagnostic splenectomy may face other potential problems. The bone disease of Gaucher's disease may be accelerated by splenectomy. ${ }^{16}$ In patients with portal hypertension and congestive splenomegaly, splenectomy may hamper future surgical portal systemic shunt procedures. ${ }^{17} \mathrm{~A}$ potential problem recently highlighted is a disturbingly high frequency of subsequent leukaemia in Hodgkin's disease patients who have had a splenectomy. ${ }^{18}$

The approach to the patient with undiagnosed splenomegaly must be individualized. The list of causes of splenomegaly is formidable; the possibilities are, however, greatly reduced by appropriate clinical evaluation and investigation. Also, for example, in the patient with infection, splenomegaly per se does not require investigation but is a useful pointer to investigation of the underlying disorder.

\section{References}

1. Wilhelm, M.C., Jones, R.E., McGehee, R., Mitchener, J.S., Sanduscy, W.R. \& Hess, C.E. Splenectomy in haematologic disorders: the ever changing indications. Ann Surg 1988, 207: $581-589$.

2. Hermann, R.E., DeHaven, K.E. \& Hawk, W.A. Splenectomy for the diagnosis of splenomegaly. Ann Surg 1968, 168: $896-900$

3. Goonewardene, A., Bourke, J.B., Ferguson, R. \& Toghill, P.J. Splenectomy for undiagnosed splenomegaly. Br J Surg 1979, 66: 62-65.

4. Bickerstaff, K.I. \& Morris, P.J. Splenectomy for massive splenomegaly. Br J Surg 1987, 74: 346-349.

5. Skarin, A.T., Davey, F.R. \& Moloney, W.C. Lymphosarcoma of the spleen. Arch Intern Med 1971, 127: 259-265.
Patients with undiagnosed splenomegaly, who are otherwise well and who have no evidence of systemic disease, particularly if the spleen is only minimally enlarged, may be followed with careful and regular observation. ${ }^{19}$ In patients who are unwell or who have evidence of systemic disease, in whom appropriate investigation (Table II) has not yielded a diagnosis, diagnostic splenectomy is a safe procedure, which in nearly all cases achieves a definitive diagnosis. In many instances, splenectomy is also therapeutic, providing relief from the consequences of splenomegaly in addition to possibly forming part of definitive therapy of the underlying condition. Patients with splenomegaly in whom a diagnosis is not reached preoperatively utilizing conventional investigations are likely to have a lymphomatous process, particularly if the spleen is grossly enlarged.

Table II Essential investigations in the patient with undiagnosed splenomegaly

Radiology
Chest X-ray
CT scan of thorax/abdomen
Barium swallow
Procedures
Liver biopsy*
Marrow aspirate
Marrow biopsy
Lymph node biopsy†
Mantoux
Kveim test
Blood
Rheumatoid factor
Anti-nuclear factor
Coombs' test
Blood cultures
Serology for HIV, hepatitides and other infections

*If not precluded by bleeding disorder; tif lymph node palpable.

6. Dacie, J.V., Brain, M.C., Harrison, C.V., Lewis, S.M. \& Worlledge, S.M. 'Non-tropical idiopathic splenomegaly' ('primary hypersplenism'): a review of ten cases and their relationship to malignant lymphoma. $\mathrm{Br} J$ Haematol 1969 , 17: $317-333$.

7. Dacie, J.V., Galton, D.A.G., Gordon-Smith, E.C. \& Harrison, C.V. Non-tropical 'idiopathic splenomegaly': a followup study of ten patients described in 1969. Br J Haematol 1978, 38: 185-193.

8. Ahmann, D.L., Kiely, J.M. \& Harrison, E.G. Malignant lymphoma of the spleen: a review of 49 cases in which the diagnosis was made at splenectomy. Cancer 1966, 19: 461-469. 
9. Morel, P., Dupriez, B., Gosselin, B. et al. Role of early splenectomy in malignant lymphomas with prominent splenic involvement (primary lymphomas of the spleen). Cancer 1993, 71: 207-215.

10. Kehoe, J. \& Straus, D.J. Primary lymphoma of the spleen. Cancer 1988, 62: 1433-1438.

11. Hardy, R. \& Horning, S.J. Molecular biologic studies in the clinical evaluation of non-Hodgkin's lymphoma. Hematol Oncol Clin North Am 1991, 5: 890-891.

12. Grogan, T.M. \& Miller, T.P. New biologic markers in non-Hodgkin's lymphomas. Hematol Oncol Clin North Am 1991, 5: 925-933.

13. Harrington, W.J. \& Harrington, T.J. Is splenectomy an outmoded procedure? Adv Intern Med 1990, 35: 415-440.

14. Crosby, W.H. Splenectomy: in and out of fashion. Arch Intern Med 1985, 145: 225-227.
15. Teare, L. \& O'Riordan, S. Is splenectomy another indication for Haemophilus influenzae type b vaccination? Lancet 1992, 340: 1362 (letter)

16. Rose, J.S., Grabowski, G.A., Barnett, S.H. \& Desnick, R.J. Accelerated skeletal destruction after splenectomy in Gaucher type 1 disease. Am $J$ Roentgenol 1982, 139: 1202-1204.

17. Warren, W.D., Zeppa, R. \& Foman, J.J. Selective transsplenic decompression of gastroesophageal varices by distal splenorenal shunt. Ann Surg 1967, 166: 437-455.

18. Van Leeuwen, F.E., Sowers, R. \& Hart, A.A.M. Splenectomy in Hodgkin's disease and second leukaemias. Lancet 1987, ii: 210-211.

19. Lin Yin, J.A. Splenomegaly. In: Delamore, I.W. \& Lin Yin, J.A. (eds) Haematological Aspects of Systemic Disease. Bailiere Tindall, London, 1990, pp. 467-489. 